\title{
Acetabular Cup Revision
}

\author{
Young-Ho Kim, MD, PhD \\ Department of Orthopedic Surgery, Hanyang University Guri Hospital, Guri, Korea
}

The use of acetabular cup revision arthroplasty is on the rise as demands for total hip arthroplasty, improved life expectancies, and the need for individual activity increase. For an acetabular cup revision to be successful, the cup should gain stable fixation within the remaining supportive bone of the acetabulum. Since the patient's remaining supportive acetabular bone stock plays an important role in the success of revision, accurate classification of the degree of acetabular bone defect is necessary. The Paprosky classification system is most commonly used when determining the location and degree of acetabular bone loss. Common treatment options include: acetabular liner exchange, high hip center, oblong cup, trabecular metal cup with augment, bipolar cup, bulk structural graft, cemented cup, uncemented cup including jumbo cup, acetabular reinforcement device (cage), trabecular metal cup cage. The optimal treatment option is dependent upon the degree of the discontinuity, the amount of available bone stock and the likelihood of achieving stable fixation upon supportive host bone. To achieve successful acetabular cup revision, accurate evaluation of bone defect preoperatively and intraoperatively, proper choice of method of acetabular revision according to the evaluation of acetabular bone deficiency, proper technique to get primary stability of implant such as precise grafting technique, and stable fixation of implant are mandatory.

Key Words: Hip, Arthroplasty, Replacement, Reoperation, Hip prosthesis

\section{INTRODUCTION}

The use of acetabular cup revision is on the rise as demands for total hip arthroplasty, improved life expectancies and the need for individual activity increase ${ }^{1)}$. Despite decreased wear rates and advancement in bearing surfaces, acetabular

Submitted: July 3, 2017 1st revision: July 26, 2017

Final acceptance: August 2, 2017

Address reprint request to

Young-Ho Kim, MD, PhD

Department of Orthopaedic Surgery, Hanyang University Guri

Hospital, 153 Gyeongchun-ro, Guri 11923, Korea

TEL: +82-2-2290-8485 FAX: +82-2-2299-8774

E-mail: Kimyh1ahanyang.ac.kr

This is an Open Access article distributed under the terms of the Creative Commons Attribution Non-Commercial License (http://creativecommons. org/licenses/by-nc/4.0) which permits unrestricted non-commercial use, distribution, and reproduction in any medium, provided the original work is properly cited. revision is inevitable in cases of subsequent cup loosening caused by bone loss resulted from acetabular osteolysis due to wear particulate debris from bearing surfaces. In addition, acetabular revision is commonly performed in cases of hip instability caused by malpositioning of the acetabular cup.

\section{CLASSIFICATION OF ACETABULAR BONE DEFICIENCY}

For an acetabular cup revision to be successful, bone growth should be achieved with stable cup placement and fixation within the remaining supportive bone of the acetabulum. Since the amount of remaining supportive acetabular bone stock in the patient plays an important role in the success of revision, proper classification of the degree of acetabular bone defect is necessary preoperatively. The popular classification systems for acetabular bone defect include the American Academy of Orthopedic Surgeons (AAOS) and Paprosky classification systems. The AAOS classification system 
was first described in 1989 by D'Antonio et al. ${ }^{2}$, which divides bone defects into segmental and cavitary patterns. Although this system categorizes the presence of pelvic discontinuity separately, it has limitations in reflecting the location and size of acetabular defect. For this reason, the Paprosky classification was developed to help select an appropriate revision cup according to acetabular defect type, size and location ${ }^{3}$. In Paprosky type 2 defects, the acetabular walls are compromised and migration of the acetabular component is less than $3 \mathrm{~cm}$. In Paprosky type 3 defects, the acetabular wall and columns are compromised and migration of the acetabular component is more than $3 \mathrm{~cm}$. Since there are challenges in choosing an appropriate acetabular cup in Paprosky type 3 defects, careful selection of the acetabular component is mandatory (Table 1).

\section{TREATMENT APPROACHES}

Several surgical techniques for acetabular cup revision are available including acetabular liner exchange, high hip center, oblong cup, trabecular metal cup with augment, bipolar cup, bulk structural graft, cemented cup, uncemented cup including jumbo cup, acetabular reinforcement device (cage), trabecular metal cup cage and others. The optimal treatment option can be chosen depending on circumstances (Fig. 1) ${ }^{4}$.

Acetabular liner exchange is a revision surgery option best suited for cases involving large periacetabular osteolysis but maintained acetabular cup stability. With an intact liner locking mechanism, chip bone graft can be performed through screw holes after screw removal. When the liner locking mechanism fails, a liner is fixed with cement after screw removal. Disadvantages of this technique are insufficient bone grafting and higher rates of postoperative dislocation ${ }^{5}$.

Acetabular cup removal is primarily indicated for cases where there are difficulties in achieving acetabular stability despite impaction chip bone graft through screw holes of the acetabular cup due to a high degree of bone loss around the acetabular component. Additionally, this technique can be applied when performing secure fixation of the acetabular polyethylene liner due to severe damage to the liner locking mechanism. Moreover, acetabular cup removal is conducted when severe damage and deformity are present in the metal shell of the acetabular cup as the femoral head penetrates through the acetabular polyethylene liner. After complete exposure of the border following removal of soft tissues and osteophytes surrounding the acetabular component, the interface between the acetabular cup and the acetabular bone is isolated circularly using the curved osteotome. Additionally, using the Explant Acetabular Cup Removal System (Zimmer, Warsaw, IN, USA), the space between the cup and the acetabular bone can be effectively separated by rotating the osteotome around the acetabular cup.

The common treatment options for acetabular cup revision are described below. Acetabular cup revision can be performed using uncemented cups for type $2 \mathrm{~A}$ and type $2 \mathrm{~B}$, and uncemented cup with medial chip bone graft for type $2 \mathrm{C}$. In type $3 \mathrm{~A}$ defects, the jumbo cup is chosen for spherical shape and high hip center, and trabecular metal cup, cemented cup, oblong cup and bulk structural graft are chosen for oblong shape.

In type 3B defects without discontinuity, cage with chip bone graft, trabecular metal cup with augment and bulk structural graft are used, in type 3B defects with discontinuity, cage or trabecular metal cup with internal plate, trabecular metal cup cage and acetabular transplant can be selected.

The most important factor determining the likely success of acetabular cup revision is obtaining primary stability through stable placement and fixation of the acetabular cup on the remaining host acetabular bone stock and tight compact chip bone graft.

In cases when jumbo cups are used, achieving intrinsic cup stability is essential for successful surgery through wedge fit by maintaining posterior bone stock, antero-superior acetabulum and ischial area, and grafting with chip bone as small as possible is desirable ${ }^{6,7)}$.

Table 1. Paprosky Classification System for Acetabular Defect

\begin{tabular}{lcccc}
\hline \hline Type & $\begin{array}{c}\text { Superior hip } \\
\text { center migration }\end{array}$ & $\begin{array}{c}\text { Ischial } \\
\text { osteolysis }\end{array}$ & Kohler line & Tear drop \\
\hline I & Minimal & None & Intact & Intact \\
IIA & Mild & Mild & Intact & Intact \\
IIB & Moderate & Mild & Intact & Moderate lysis \\
IIC & Mild & Mild & Disrupted & Moderate lysis \\
IIIA & Severe & Moderate & Intact & Severe lysis \\
IIIB & Severe & Severe & & Disrupted \\
\hline
\end{tabular}


Young-Ho Kim Acetabular Cup Revision

When intrinsic cup stability is challenging with a jumbo cup, it is necessary to choose a cage or a trabecular metal cup with augment alternatively.
When using cages to promote stability of cage strong impaction of chip bone graft, a sufficient number of screws (as many as 3 or 4), and secure fixation of screws on good

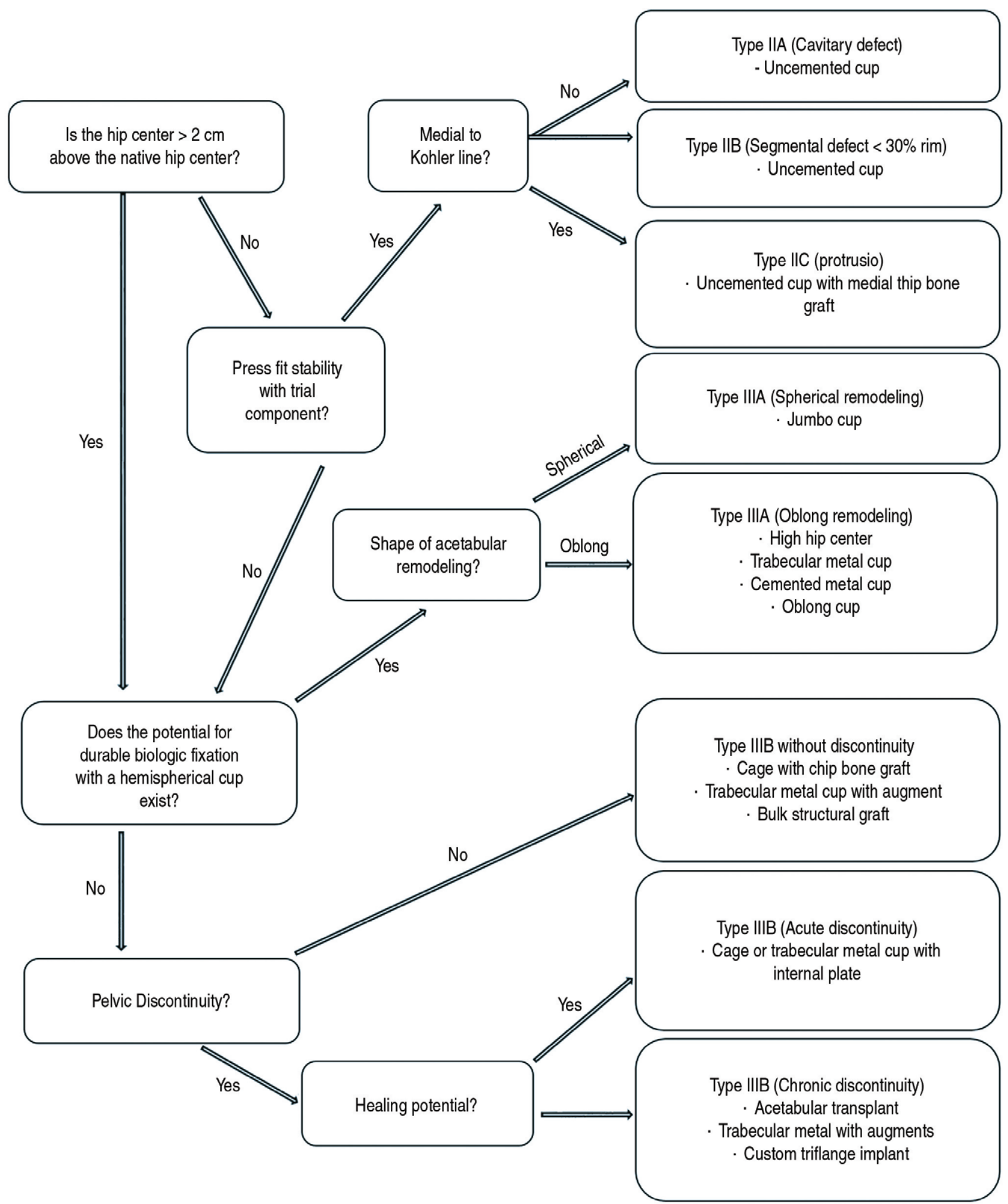

Fig. 1. Treatment algorithm for management of acetabular bone defect. 
bone stock are mandatory ${ }^{8-10)}$.

In cases where trabecular metal augments are used, the cup size should be determined to obtain relative stability by performing expanded reaming until two points of fixation are achieved. Initially, the augment should be securely fixed on the host bone in the acetabular bone defect with multiple screws. Subsequently, intrinsic stability of cup is obtained by reaming for an optimum contact between the metal shell cup and the augment, as well as the host bone surface, and overall primary cup stability should be achieved through additional screw fixation ${ }^{11-14)}$.

In recent years, to improve the relatively high failure rate of the antiprotrusio cage at long-term follow up, acetabular cup revision using a cup cage construct has been suggested. In this combined procedure using cage and trabecular metal shell, fixation is established for partial stability through the trabecular metal shell, then be reinforced using a cage for secure initial stability, and favorable short-term clinical results have been reported ${ }^{15}$.

Custom triflange implants are used for patients with massive acetabular bone loss and pelvic discontinuity. By manufacturing and inserting implants after obtaining reconstruction images using 3-dimensional computed tomography, favorable shortterm clinical outcomes have been reported ${ }^{16)}$.

With recent advances in implants, a variety of acetabular reconstruction options have been introduced. Selecting the optimal treatment option can be chosen according to patient factors, including the degree of acetabular defect. However, choosing the most effective treatment modality should also be based on the long-term outcomes of well-designed clinical studies of recently developed implants.

\section{CONCLUSION}

The keys to achieving successful acetabular cup revision include: i) accurate evaluation of bone defect preoperativey and intraoperatively; ii) choosing the proper method of acetabular revision according to the evaluation of acetabular bone deficiency; and iii) applying the proper technique to achieve primary implant stability (e.g., precise grafting technique, and stable implant fixation).

\section{CONFLICT OF INTEREST}

The author declares that there is no potential conflict of interest relevant to this article.

\section{REFERENCES}

1. Kurtz S, Mowat F, Ong K, Chan N, Lau E, Halpern M. Prevalence of primary and revision total hip and knee arthroplasty in the United States from 1990 through 2002. J Bone Joint Surg Am. 2005;87:1487-97.

2. D'Antonio JA, Capello WN, Borden LS, et al. Classification and management of acetabular abnormalities in total hip arthroplasty. Clin Orthop Relat Res. 1989;(243):126-37.

3. Paprosky WG, Perona PG, Lawrence JM. Acetabular defect classification and surgical reconstruction in revision arthroplasty. A 6-year follow-up evaluation. J Arthroplasty. 1994;9:33-44.

4. Sporer SM, O'Rourke M, Paprosky WG. The treatment of pelvic discontinuity during acetabular revision. J Arthroplasty. 2005;20(4 Suppl 2):79-84.

5. Terefenko KM, Sychterz CJ, Orishimo K, Engh CA Sr. Polyethylene liner exchange for excessive wear and osteolysis. J Arthroplasty. 2002;17:798-804.

6. Gustke KA, Levering MF, Miranda MA. Use of jumbo cups for revision of acetabulae with large bony defects. $J$ Arthroplasty. 2014;29:199-203.

7. von Roth P, Abdel MP, Harmsen WS, Berry DJ. Uncemented jumbo cups for revision total hip arthroplasty: a concise followup, at a mean of twenty years, of a previous report. J Bone Joint Surg Am. 2015;97:284-7.

8. Kerboull M, Hamadouche M, Kerboull L. The Kerboull acetabular reinforcement device in major acetabular reconstructions. Clin Orthop Relat Res. 2000;(378):155-68.

9. Bostrom MP, Lehman AP, Buly RL, Lyman S, Nestor BJ. Acetabular revision with the Contour antiprotrusio cage: 2to 5-year followup. Clin Orthop Relat Res. 2006;453:188-94.

10. Okano K, Miyata N, Enomoto H, Osaki M, Shindo H. Revision with impacted bone allografts and the Kerboull cross plate for massive bone defect of the acetabulum. J Arthroplasty. 2010;25:594-9.

11. Del Gaizo DJ, Kancherla V, Sporer SM, Paprosky WG. Tantalum augments for Paprosky IIIA defects remain stable at midterm followup. Clin Orthop Relat Res. 2012;470: 395-401.

12. Flecher X, Sporer S, Paprosky W. Management of severe bone loss in acetabular revision using a trabecular metal shell. J Arthroplasty. 2008;23:949-55.

13. Lingaraj K, Teo YH, Bergman N. The management of severe acetabular bone defects in revision hip arthroplasty using modular porous metal components. J Bone Joint Surg Br. 2009;91:1555-60.

14. Weeden SH, Schmidt RH. The use of tantalum porous metal implants for Paprosky $3 A$ and $3 B$ defects. J Arthroplasty. 2007;22(6 Suppl 2):151-5.

15. Abolghasemian M, Tangsaraporn S, Drexler M, et al. The challenge of pelvic discontinuity: cup-cage reconstruction does better than conventional cages in mid-term. Bone Joint J. 2014;96-B:195-200.

16. Taunton MJ, Fehring TK, Edwards P, Bernasek T, Holt GE, Christie MJ. Pelvic discontinuity treated with custom triflange component: a reliable option. Clin Orthop Relat Res. 2012; 470:428-34. 